\title{
Early Development and Cleavage Pattern of the Japanese Purple Mussel, Septifer virgatus
}

\author{
Yoshihisa Kurita $^{1 *}$, Ryusaku Deguchi ${ }^{2}$ and Hiroshi Wada ${ }^{1}$ \\ ${ }^{1}$ Graduate School of Life and Environmental Sciences, University of Tsukuba, \\ Tsukuba 305-8572, Japan \\ ${ }^{2}$ Department of Biology, Miyagi University of Education, Aoba-ku, \\ Sendai, Miyagi 980-0845, Japan
}

\begin{abstract}
Despite easy access to bivalves, few studies have examined the development of these animals, at least in part because most bivalve eggs are very small. In addition, annotating cells of the early bivalve embryo is difficult because few landmarks are present. We conducted detailed cell annotations of the Japanese purple mussel, Septifer virgatus, during early embryogenesis because of its relatively large eggs (ca. $130 \mu \mathrm{m}$ in diameter). Septifer virgatus underwent the unique cell division profile reported for four other bivalve species, suggesting that the cleavage pattern itself is important for bivalve morphogenesis. The shell field invagination was led by $2 \mathrm{~d}(\mathrm{X})$ lineage cells, supporting the hypothesis that lineage cells differentiate into cells excreting the shell matrix. The large egg size enabled us to trace cell movements in the early gastrulation phase, during which the invagination of the archenteron was initiated by $4 \mathrm{~d}(\mathrm{M})$ lineage cells. These observations will serve as a basis for future analyses of $S$. virgatus embryogenesis and will contribute to understanding the evolution of the molluscan body plan, which is achieved by modification of early embryogenesis.
\end{abstract}

Key words: mussel, Septifer virgatus, mollusc, cell lineage, cleavage, shell plate, gastrulation

\section{INTRODUCTION}

Some lophotrochozoans, including molluscs, annelids, nemerteans, and polyclad turbellarians, show a characteristic spiral cleavage pattern and thus are called Spiralia. In the late 19th century, Wilson (1892), Lillie (1895), and Conklin (1897) published remarkably detailed and descriptive cell lineage accounts of some spiralians. These studies showed that conserved developmental processes are not limited to cleavage patterns but also occur in the cell lineage and development of prototrochs and mesodermal cells. More recently, experimental and molecular developmental studies have been conducted on gastropod molluscs and annelids (e.g., Clement, 1976; Henry and Martindale, 1998). However, compared with groups on which extensive studies of model species have been undertaken (e.g., flies and nematodes among ecdysozoans; sea urchins, ascidians, and vertebrates among deuterostomes), knowledge of lophotrochozoan or spiralian development is lacking. An investigation of early developmental mechanisms in spiralian phyla should help to reconstruct how developmental processes evolved in the Lophotrochozoa and across the Metazoa.

Among the spiralian phyla, molluscs vary greatly morphologically. Molluscs are characterized by having a calcite skeleton, which for most species is the shell plate. Shell

\footnotetext{
* Corresponding author. Phone: +81-29-853-4671; Fax : +81-29-853-4671; E-mail: Katachiya@gmail.com
}

morphology is reflected in classification into seven classes: Aplacophora, Polyplacophora, Monoplacophora, Bivalvia, Scaphopoda, Cephalopoda, and Gastropoda. Although the phylogenetic relationships among the classes remain uncertain, one widely accepted hypothesis proposed by molecular phylogenetic and morphological studies places the aplacophorans as the most basal mollusc group, followed by the divergence of Polyplacophora and Conchifera (SalviniPlawen and Steiner, 1996; Todt et al., 2008), with the latter group including Monoplacophora, Bivalvia, Scaphopoda, Cephalopoda, and Gastropoda. Monoplacophora is regarded as the basal taxon of the conchiferans (SalviniPlawen and Steiner, 1996). The relationship among the remaining four taxa is still debated, although the phylogenetic affinity of gastropods and cephalopods is largely accepted (Haszpunar et al., 2008).

The distinct shell morphology characteristic of each molluscan taxon is observable as early as the gastrula stage of embryogenesis. The earliest sign of conchiferan shell plate formation is the invagination of the shell field, which occurs at almost the same developmental time as gastrulation. In gastropods, which have a single shell plate, the shell field invaginates from a single spot and then evaginates, excreting a shell matrix as a single circle (Kniprath, 1981). In contrast, in bivalves, which possess bilaterally separated shell plates, the shell field invaginates much like a slit, and after evagination the shell matrix is observed as two separated plates (Kniprath, 1981; Kakoi et al., 2008). The distinct shell plate morphogenesis of gastropods and bivalves occurs subsequent to the conserved spiral cleavage pattern.

The conserved cleavage pattern of molluscs allows 
homologous blastomeres to be compared and their cell fate to be elucidated (e.g., Conklin, 1897; Dictus and Damen, 1997). The first two divisions generate four blastomeres,
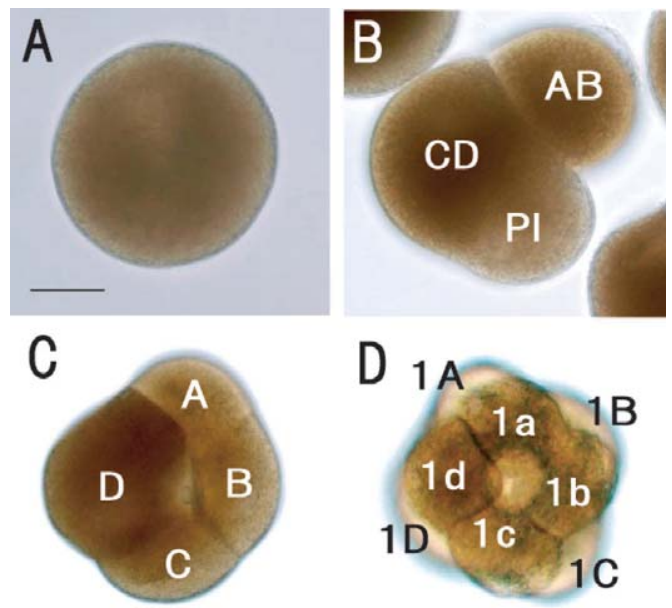

Fig. 1. Septifer virgatus embryogenesis: fertilized egg through 8cell stage. (A) Fertilized egg. (B) At $70 \mathrm{~min}$ post-fertilization (pf), after the first cleavage, the polar lobe reintegrates into the CD blastomere. (C) Animal view of a 4-cell embryo, 90 min pf. (D) Animal view of an 8-cell embryo, 120 min pf. PI, polar lobe. Scale bar: 50 $\mu \mathrm{m}$.
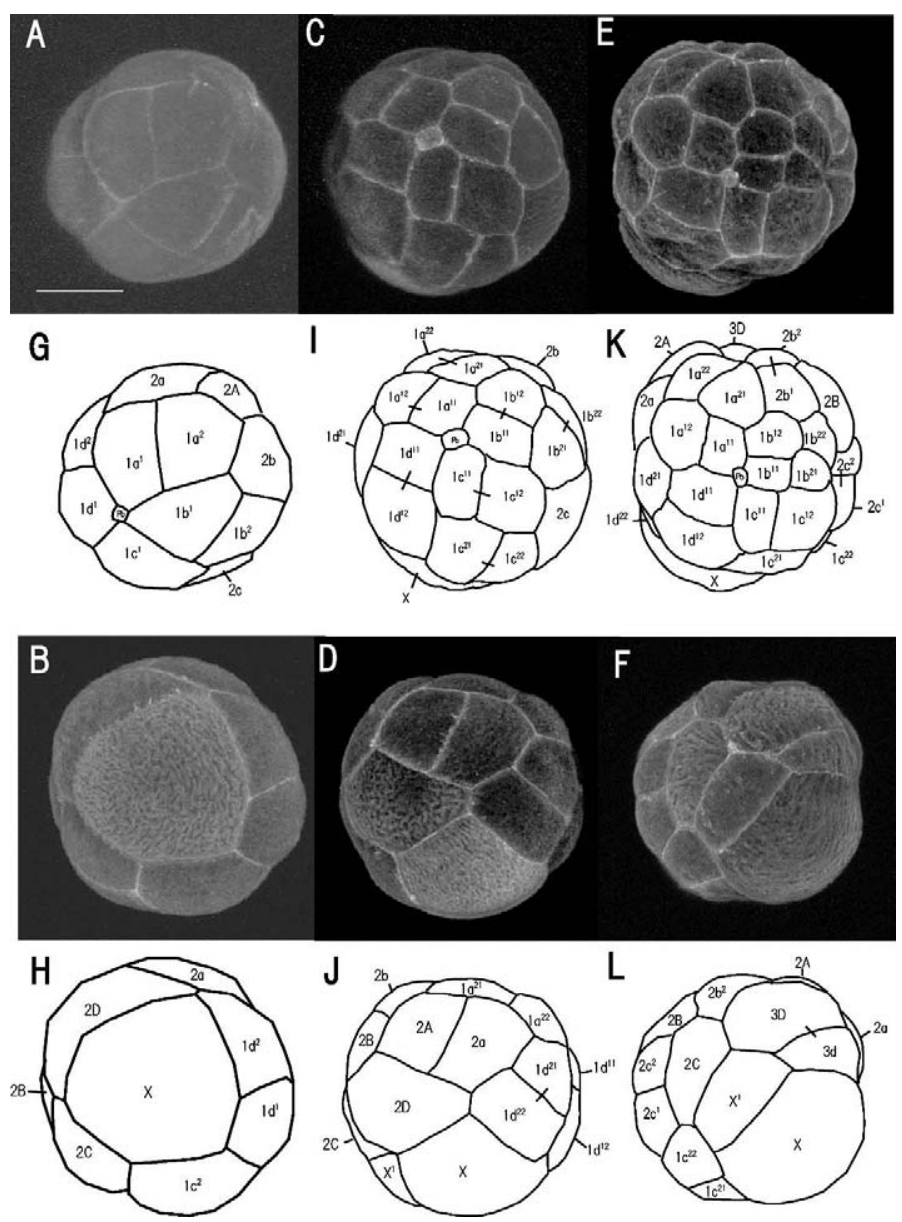

designated $A, B, C$, and $D$, which usually correspond to the left, ventral, right, and dorsal sides, respectively, of the future larval body (note that there is some variation in the orientation of the first cleavage in two species of bivalves: Dreissena polymorpha and Pholas dactylus; Meisenheimer, 1901; Luetjens and Dorresteijn, 1995; Guerrier, 1970). These blastomeres divide unequally to generate a quartet of micromeres in the animal tier, designated by lowercase letters $(a-d)$. Micromeres are not situated directly above sister macromeres, as the orientation of the spindle is oblique with respect to the animal-vegetal axis. After the first quartet of micromeres is generated, macromeres, as well as micromeres, continue to divide unequally to generate successive generations of animal micromere quartets. Thus, the largest cell in a spirally cleaving embryo is usually one of the vegetalmost macromeres. The molluscan shell plate develops on the dorsal surface of the larva, and the cells responsible for shell matrix excretion derive from the $D$ quadrant, usually $2 d$ (but also see Dictus and Damen, 1997).

Except that some modification of early cleavages was observed in the lecithotropic species Solemya reidi (Gustafson and Reid, 1986), in which the shell plates develop during metamorphosis, the early cleavage pattern is stereotypic in bivalves. The first two cell divisions are always unequal, irrespective of polar lobe formation, and thus the $D$ blastomere is always the largest of the 4-cell embryo. A unique cleavage pattern occurs in D-quadrant descendants. After the second round of micromere generation, the largest cell is not a macromere but is the $2 \mathrm{~d}$ cell, which is a daughter cell of the 1D macromere on the animal side. Of interest is that the $2 \mathrm{~d}$ cell is thought to be the founder cell of bivalve shells (Lillie, 1895; Meisenheimer, 1901). Given the importance of the $2 \mathrm{~d}$ cell and its descendants in the bivalve embryo, a special notation is used in which the $2 d$ cell and its largest descendant cell are denoted as $X$ until the bilateral cleavage stage (Lillie, 1895). X divides unequally four times, each time alternating the orientation and relative position of the mitotic spindle in the cell. The first micromere generated from the $X$ blastomere is called $X^{1}$, the second $X^{2}$, and so on, with the largest blastomere always designated $X$. In the first two cell divisions, small blastomeres are deposited vegetally, and thus $X^{1}$ and $X^{2}$ are located on the vegetal side of $X$. In the third division, $X^{3}$ is deposited animally, whereas in the fourth division $X^{4}$ is again located vegetally. This pattern has been reported for at least four bivalve species (for Unio complanata by Lillie, 1895; Dreissena polymorpha by Meisenheimer,

Fig. 2. Confocal images of $S$. virgatus embryogenesis: 16through 28-cell stages. (A-F) Confocal 3D projection images of embryos. Only the plasma membrane stained with phalloidin is evident here. (G-L) Line drawings of images $(A-F)$ in the following order: (A, G) 140 min pf: 16-cell stage, animal view. (B, H) 140 min pf: 16 -cell stage, vegetal view. (C, I) $160 \mathrm{~min}$ pf: 25-cell stage, animal view. (D, J) $160 \mathrm{~min}$ pf: 25 -cell stage, vegetal view. (E, K) 170 min pf: 28-cell stage, animal view. (F, L) 170 min pf: 28-cell stage, vegetal view. Sister blastomeres produced by division from an earlier stage are connected with a bold line. $X, 2 d$ or the largest descendant blastomere of $2 \mathrm{~d}$. Smaller descendants of $X$ are denoted as $X^{1}, X^{2}$, and so on, according to the generation of division. Scale bar: $50 \mu \mathrm{m}$. 
1901; Pholas dactylus by Guerrier, 1970; Saccostrea kegaki by Kin et al., 2009) but has never been observed in gastropods or other molluscs. After the four unequal cleavages, $X$ divides in a bilaterally symmetric manner. This unique and conserved cleavage pattern of bivalvian shell plate founder cells suggests that this cleavage pattern is intimately linked with the characteristic shell morphology of bivalves.

The $X$ descendant cells invaginate, and a dorsal invagination called the "shell field invagination" (SFI) (Eyster and Morse, 1984) appears, representing the prospective shell field. Subsequently, the shell field evaginates and emerges onto the surface. The shell field then continues to expand laterally until it covers the whole embryo. As the shell field is covering the embryo, the secretion of shell matrix and calcification in the shell field begin and continue thereafter. At almost the same time as the SFI, gastrulation occurs on the ventral side. Together with the endoderm cells, presumptive posterior mesoderm cells ( $4 \mathrm{~d}$ lineage designated as $M$ ) invaginate. Lillie (1895) described that the $M$ lineage cells of $U$. complanata enter the blastocoel before the vegetal blastomeres invaginate.

Recently, Kin et al. (2009) presented evidence from S. kegaki that specific expression of the signaling molecule decapentaplegic (Dpp) might be involved in the development of the bivalvian separated shell plate. The oyster $d p p, S k D p p$, is expressed in cells that clip the bivalvian shell plate anlage from the anterior and posterior. Because exogenous addition of Dpp during shell plate formation leads to the morphogenesis of a small shell plate, Dpp may repress cell proliferation at the dorsal midline of the bivalve shell anlage and thus lead to separation of the shell field into two distinct plate anlages (Kin et al., 2009).

However, the small egg size of most bivalves (e.g., in Saccostrea kegaki the egg diameter is $<50 \mu \mathrm{m}$ ) prevents observations of morphogenesis before the late embryonic stage and experimental analysis, such as the micromanipulation of embryos. We investigated the cleavage pattern of the Japanese purple mussel, Septifer virgatus, a bivalve with larger $(\sim 130 \mu \mathrm{m})$ and more robust embryos than those of $S$. kegaki. Using a confocal laser-scanning microscope to observe the cleavage pattern, we detected a cleavage pattern that was highly conserved in $S$. kegaki and $S$. virgatus. We also took advantage of the large embryo size to observe the blastomeres initiating gastrulation and present evidence here that $S$. virgatus gastrulation is initiated from the $M$ lineage. We also observed the symmetric division of $X$ and demonstrated that the shell field invagination of bivalves is initiated from $X$ lineages.

\section{MATERIALS AND METHODS}

\section{Embryo collection}

Adult S. virgatus were collected at Kashima Port, Ibaraki, Japan. Mature eggs and sperm could be obtained from July to September in this location. Spawning was induced by heat-shock treatment with warm filtered-seawater $(\mathrm{FSW})$ at $50^{\circ} \mathrm{C}$. After the heat shock, individual animals were kept separately in small containers. In a few hours, about half the individuals spawned mature eggs or sperm. The spawned eggs had already completed germinal vesicle breakdown, and were ready to be fertilized. In-vitro fertilization was accomplished by adding diluted sperm to the eggs. Although the fertilized eggs were covered by a thin membrane, this membrane was hardly visible under the light microscope because it was tightly attached to the plasma membrane. Embryos were cultured in $\mathrm{FSW}$ at $27^{\circ} \mathrm{C}$. We usually transferred swimming gastrulas about $6 \mathrm{~h}$ after fertilization into fresh FSW at a density of less than 100 larvae $/ \mathrm{ml}$. The density of larvae is critical for the normal development of swimming gastrulas into $D$ shaped larvae.

\section{Fluorescence staining and observation with confocal laser- scanning microscopy}

Embryos were fixed in 4\% paraformaldehyde, 0.1 M MOPS (3[N-morpholino] propanesulfonic acid; pH 7.5), 2 mM EGTA, and 0.5 $\mathrm{M} \mathrm{NaCl}$ and stored in $0.1 \%$ sodium azide in PBS at $4^{\circ} \mathrm{C}$. Embryos were stained with YOYO-1 fluorescent dye (Invitrogen, Carlsbad, $\mathrm{CA}$ ) to visualize chromosomes and rhodamine-phalloidin (Invitrogen) to visualize cell boundaries. Prior to staining with YOYO-1, embryos were treated with $1 \mathrm{mg} / \mathrm{ml}$ RNase in PBS at $37^{\circ} \mathrm{C}$ for $2 \mathrm{~h}$
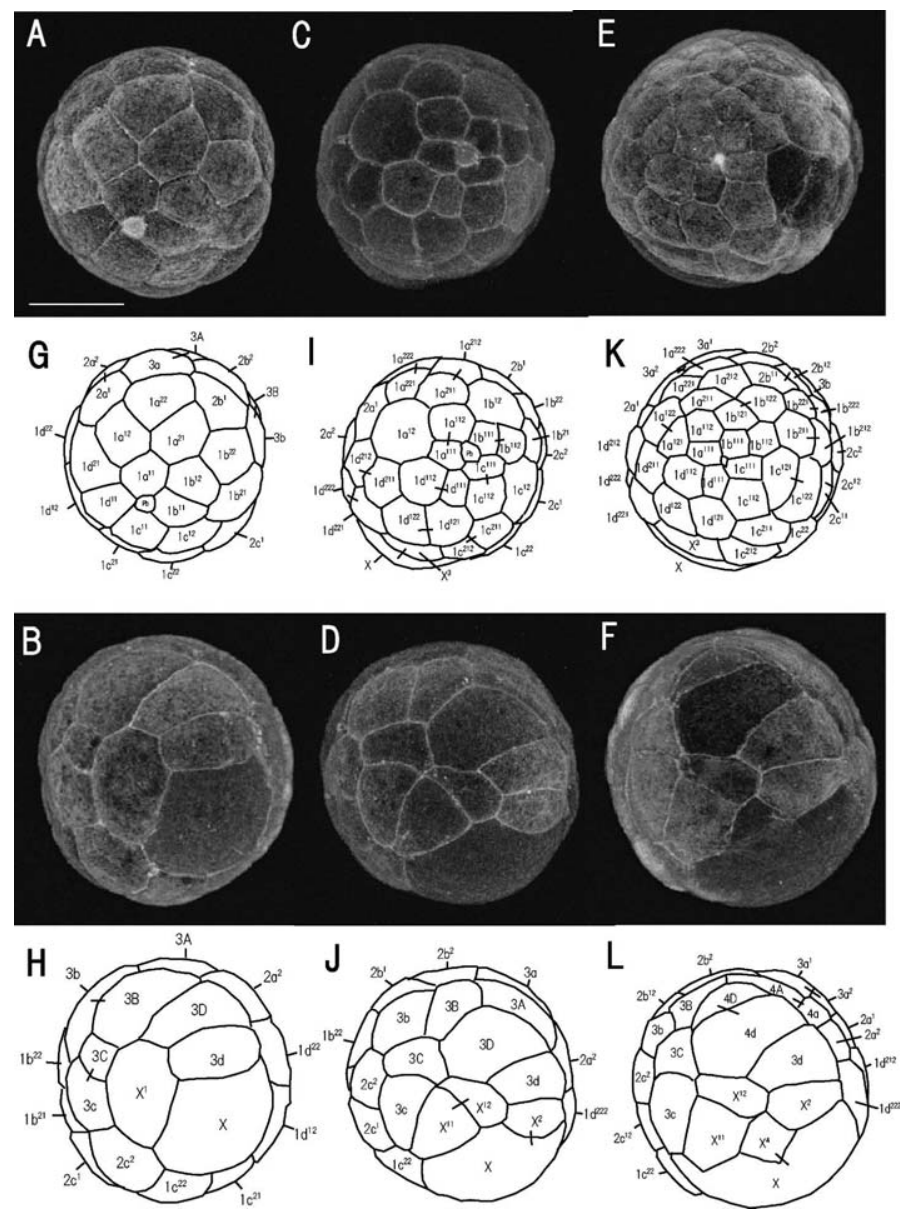

Fig. 3. Confocal images of $S$. virgatus embryogenesis: 32- through 58cell stages. (A-F) Confocal 3D projection images of embryos. Only the plasma membrane stained with phalloidin is evident here. (G-L) Line drawings of images (A-F) in the following order: $(A, G) 180 \mathrm{~min}$ pf: 32-cell stage, animal view. (B, H) $180 \mathrm{~min}$ pf: 32-cell stage, vegetal view. (C, I) 200 min pf: 45-cell stage, animal view. (D, J) 200 min pf: 45-cell stage, vegetal view. (E, K) $210 \mathrm{~min}$ pf: 58-cell stage, animal view. (F, L) $210 \mathrm{~min}$ pf: 58 -cell stage, vegetal view. Sister blastomeres produced by division from an earlier stage are connected with a bold line. $X, 2 \mathrm{~d}$ or the largest descendant blastomere of $2 \mathrm{~d}$. Smaller descendants of $X$ are denoted as $\mathrm{X}^{1}, \mathrm{X}^{2}$, and so on. Scale bar: $50 \mu \mathrm{m}$. 
to destroy cytoplasmic RNA. Embryos were then stained with 10 unit/ml rhodamine-phalloidin in PBT [PBS $+0.1 \%$ Tween20] for about $1 \mathrm{~h}$ at room temperature, followed by staining with $1 \mu \mathrm{M}$ YOYO-1 in PBS for $5 \mathrm{~min}$ at room temperature. The embryos were subsequently washed three times with PBS and mounted in $50 \%$ glycerol for observation. Optical sectioning images in the Z-axis $(1.5 \mu \mathrm{m} /$ slice) were obtained with a Zeiss LSM510 confocal laser-scanning microscope. Projection images were reconstructed in 3D from the Z-series images by using Zeiss LSM Image Browser. The projected images were traced onto paper by hand, and individual blastomeres were then identified. Because the embryos of $\mathrm{S}$. virgatus is rich in yolk and not very transparent, embryos were mounted between two coverslips, and the same embryo was observed from two angles by using H-S Slideframework (Fujiwara Scientific Company).

To trace the cleavage pattern by examining fixed material, we collected embryos every $5 \mathrm{~min}$ until the embryos underwent gastrulation and SFI at $8 \mathrm{~h}$ post-fertilization (pf). Because very little cell movement was observed before gastrulation, we could trace descendent cells through their relative position and shape. Occasionally the relative position of the blastomeres seemed shifted, probably because the cell contact was relatively loose at this stage (e.g., the relative positions of 2A-3A and 3D in Fig. 2L and Fig. 3H, $\mathrm{J})$. Even in this case, we could confidently annotate blastomeres by the relative position of surrounding blastomeres. In this procedure, rotation of the 3D projection images helped a lot, because the relative position of each cell could be compared from the same angle of view. Sometimes chromosome visualization enabled us to distinguish mitotic-phase chromosomes from gapphase chromosomes, thus helping us determine the order of cell cleavage.

\section{RESULTS}

\section{Cleavage pattern of S. virgatus to the 67- cell stage}

The diameter of fertilized $S$. virgatus eggs was approximately $130 \mu \mathrm{m}$ (Fig. 1A). We observed the polar lobe at approximately $60 \mathrm{~min}$ pf (Fig. 1B). After the polar lobe appeared, the first cleavage occurred at $70 \mathrm{~min}$ pf. The polar lobe was incorporated into one of the sister cells, resulting in an embryo of two cells of very different sizes. Polar lobe formation occurred again at the following cell division, producing one large blastomere ( $\mathrm{D}$ blastomere) and three smaller blastomeres of similar size, referred to as the $A, B$, and $C$ blastomeres (Fig. 1C). At approximately $120 \mathrm{~min}$ pf, embryos reached the 8-cell stage, with the typical spiralian arrangement of blastomeres, i.e., smaller blastomeres (1a, 1b, 1c, 1d) occupied the animal half, sitting slightly dextral to the vegetal "macromeres" (1A, 1B, 1C, 1D) (Fig. 1D). By $140 \mathrm{~min}$ pf, the embryos reached the 16-cell stage, with $2 d(X)$ the largest blastomere, as in other bivalves (Fig. 2A, B: 16-cell stage). Subsequently, $X$ and so on. divided unequally into a smaller $X^{1}$ sitting vegetally and larger $X$ sitting animally. By $160 \mathrm{~min}$ pf, the first quartets (1q) completed the fifth cell division (Fig. 2C, D: 25-cell stage). We observed the division of $2 b$, followed by that of $2 c$ and 2D at 170 min pf (Fig. 2E, F: 28-cell stage). At approximately $180 \mathrm{~min}$ pf, the embryos reached the 32-cell stage by divisions of $2 \mathrm{a}, 2 \mathrm{~A}, 2 \mathrm{~B}$, and $2 \mathrm{C}$ (Fig. $3 \mathrm{~A}, \mathrm{~B}$ : 32-cell stage). By $200 \mathrm{~min}$ pf, the embryos reached the 45 -cell stage by the divisions of $1 a^{11}, 1 a^{21}, 1 a^{22}, 1 b^{11}, 1 c^{11}, 1 c^{21}, 1 d^{11}, 1 d^{12}$, $1 d^{21}, 1 d^{22}, X$, and $X^{1}$ (Fig. 3C, D: 45-cell stage). By this
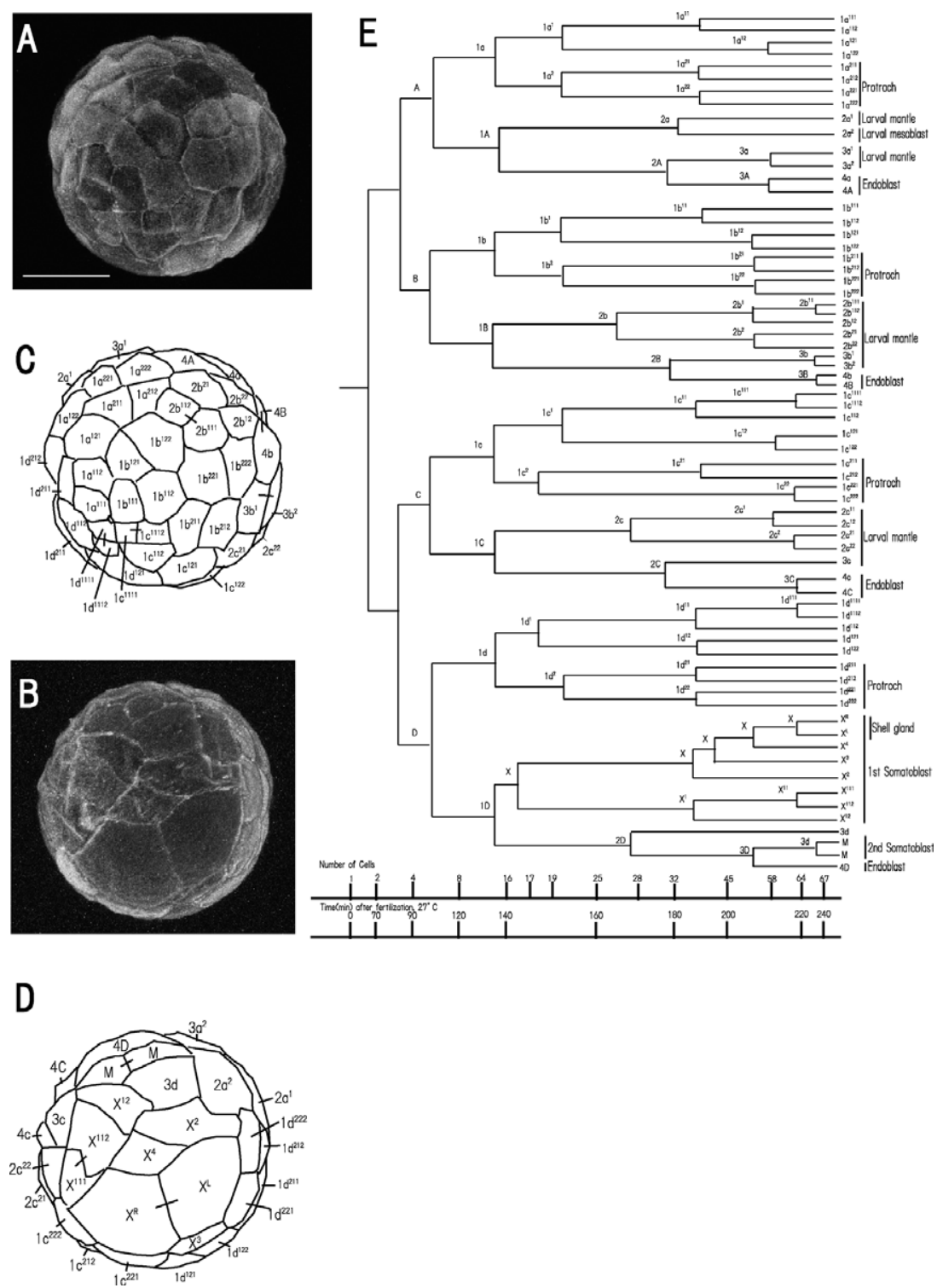

Fig. 4. Confocal images of 67-cell embryos and summary of the $S$. virgatus cell lineage. (A, B) Confocal 3D projection images of embryos. Only the plasma membrane stained with phalloidin is evident here. (C, D) Line drawings of images $(A, B)$ in the following order: (A, C) 240 min pf: 67-cell stage, animal view. (B, D) 240 min pf: 67-cell stage, vegetal view. Scale bar: $50 \mu \mathrm{m}$. Sister blastomeres produced by division from an earlier stage are connected with a bold line. (E) Cell cleavage tree showing the timing of cell division for each blastomere up to the 67-cell stage. The cell fates of blastomeres were taken from Lillie (1895) and Kakoi et al. (2008). X, 2d or the largest descendant blastomere of $2 \mathrm{~d}$; M, $4 \mathrm{~d}$ descendant blastomere. The smaller descendants of $\mathrm{X}$ are denoted as $\mathrm{X}^{1}, \mathrm{X}^{2}$, 
stage, $\mathrm{X}$ had completed the third unequal cell division, bearing $X^{2}$ to the vegetal side and $X^{3}$ to the animal side. At approximately $210 \mathrm{~min} \mathrm{pf}$, the embryos reached the 58-cell stage by divisions of $1 a^{12}, 3 a, 1 b^{12}, 1 b^{21}, 1 b^{22}, 2 b^{1}, 2 b^{2}$, $1 c^{12}, 2 c^{1}, X$, and 3D (Fig. 3E, F: 58-cell stage), followed by divisions of $1 c^{111}, 1 c^{22}, 2 c^{2}, 3 C, 1 d^{111}$, and $X$ to achieve the 64-cell stage at about 220 min pf. At approximately $240 \mathrm{~min}$ $\mathrm{pf}$, the embryo reached the 67 -cell stage by division of $2 \mathrm{~b}^{11}$, 3b, 3B, and 3d (Fig. 4C, D: 67-cell stage). This fifth cell division of $X$ occurred in a bilaterally symmetric manner, yielding $X^{L}$ and $X^{R}$. Fig. 4E summarizes the cleavage pattern of S. virgatus.

\section{Further cell divisions of $X$ and shell field invagination}

As described above, the $X$ blastomere underwent four asymmetric cell divisions by the 58-cell stage. The first two divisions yielded two small blastomeres on the vegetal side of $X\left(X^{1}\right.$ and $\left.X^{2}\right)$; in the third unequal cleavage, the chromo-

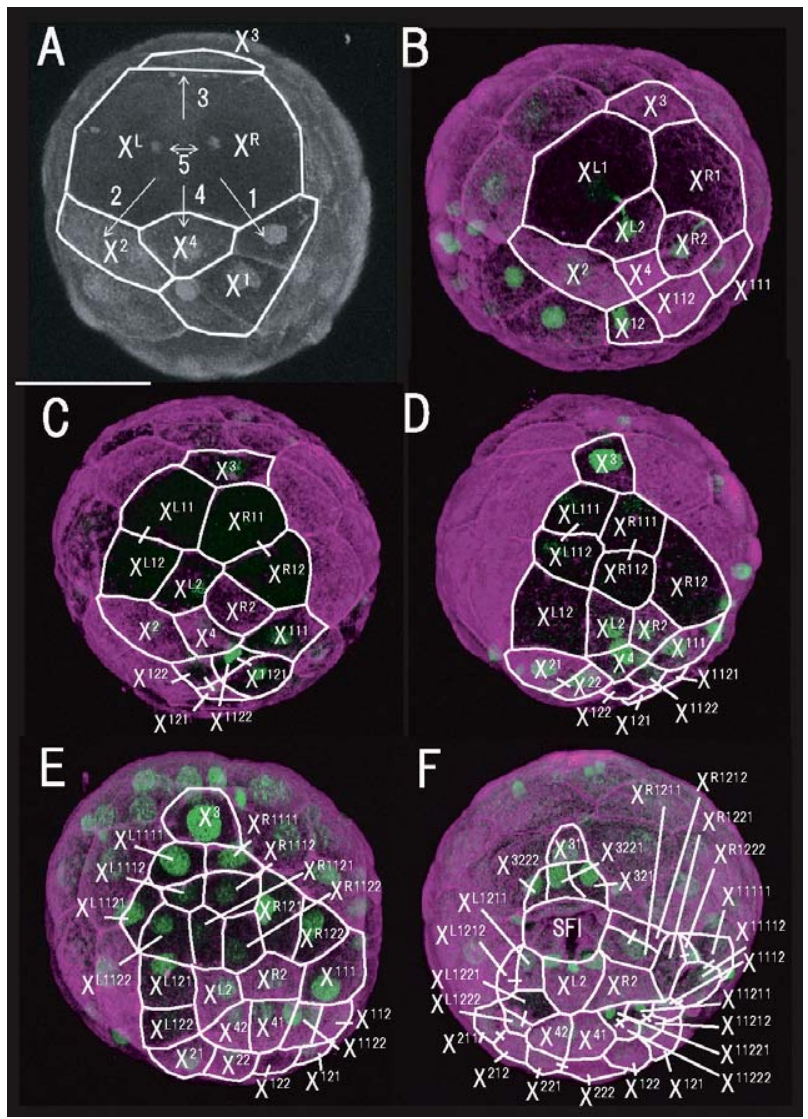

Fig. 5. Cleavage pattern of $X$ lineage cells to the shell field invagination stage. Confocal 3D projection images of embryos. Nuclei were visualized by staining with YOYO-1, and the plasma membrane was stained with phalloidin. (A) Summary of the cleavage pattern of $X$ to the bilaterally symmetric cell division (67-cell stage). White arrows indicate the movement of chromosomes at each cell division. (B-F) Cleavage pattern of $X$ blastomeres to the SFI stage. Daughter blastomeres after a cell division are connected with a bold line. Some cells appear to have more than one nucleus. This is because the cells are tightly packed at this stage, and the nuclei of the cells lying behind are visible. SFI, shell field invagination. Scale bar: $50 \mu \mathrm{m}$. somes moved to the dorsal midline of the animal pole, with a small blastomere on the anterior side $\left(X^{3}\right)$. Before the fourth cell division, the chromosomes moved vegetally again, yielding $X^{4}$ on the vegetal side. After these four asymmetric cell divisions, $X$ divided symmetrically. This unique cleavage pattern is identical to that observed in three other bivalves (Lillie, 1895; Meisenheimer, 1901; Kin et al., 2009; Fig. 5A).

Taking advantage of the large egg size of S. virgatus, we followed further cell divisions to the shell field invagination stage. After the symmetric division, both $X^{L}$ and $X^{R}$ underwent asymmetric cell divisions, yielding small blastomeres vegetally ( $\mathrm{X}^{\mathrm{L} 2}$ and $\mathrm{X}^{\mathrm{R} 2}$; Fig. $\left.5 \mathrm{~B}\right)$. The next cell divisions of $X^{L 1}$ and $X^{R 1}$ were almost equal, but cleavage occurred along the animal-vegetal axis, with one cell to the animal side and the other to the vegetal (Fig. 5C-E). The $X^{L}-X^{R}$ blastomeres then divided rapidly (5 times within $120 \mathrm{~min}$ ). These rapid divisions were remarkably synchronized between the $\mathrm{X}^{\mathrm{L}}$ and $\mathrm{X}^{\mathrm{R}}$ lineages, with symmetric division patterns on either side of the dorsal midline (Fig. 5C-E). About $30 \mathrm{~min}$ after the bilaterally symmetric cell division yielding $X^{L}$ and $X^{R}$ ( $6 \mathrm{~h} \mathrm{pf),} \mathrm{shell} \mathrm{field} \mathrm{invagination} \mathrm{was} \mathrm{initi-}$ ated in the region occupied by $X^{L 1}$ and $X^{R 1}$ descendents (Fig. 5F). After shell field invagination, we could not annotate the blastomeres, as extensive migration occurred along with shell field invagination and gastrulation.

\section{Gastrulation site of S. virgatus}

At almost the same time as shell field invagination, gas-
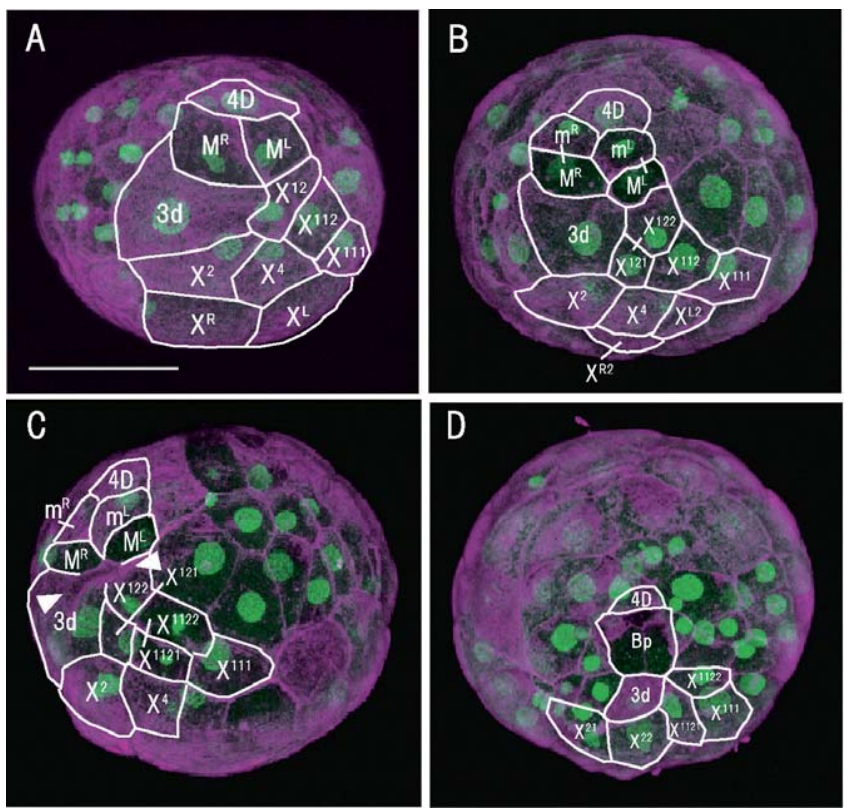

Fig. 6. Cell divisions and cell movements during the gastrulation in S. virgatus embryos stained with phalloidin and YOYO-1. (A) Vegetal view of a 230 min pf embryo. (B) Vegetal view of a 270 min pf embryo. (C) Vegetal view of a 300 min pf embryo. (D) Vegetal view of a 360 min pf embryo. Daughter blastomeres after a cell division are connected with a bold line. Some cells appear to have more than one nucleus. This is because the cells are tightly packed at this stage, and nuclei of the cells lying behind are visible. Bp, blastopore. Scale bar: $50 \mu \mathrm{m}$. 
trulation began on the opposite side of the embryos. We traced cell movements during the early phase of gastrulation, paying particular attention to the cells initiating invagination. After the 64-cell stage, 4d divided in a bilaterally symmetric manner into $M^{L}$ and $M^{R}$. These cells are thought to be the precursor cells of the endomesoderm (posterior mesoderm) and are given the special annotation $M$ (Lillie, 1895; Meisenheimer, 1901; Fig. 6A). $M^{L}$ and $M^{R}$ divided asymmetrically, yielding $\mathrm{m}^{\mathrm{L}}$ and $\mathrm{m}^{\mathrm{R}}$, respectively (Fig. 6B). After this cell division, gastrulation was initiated on the vegetal side of $\mathrm{M}^{\mathrm{L}}$ and $\mathrm{M}^{\mathrm{R}}$ (Fig. $6 \mathrm{C}$ ). The $\mathrm{M}$ lineages had completely invaginated $6 \mathrm{~h}$ pf (Fig. 6D). Thus, in S. virgatus, M lineage cells lead to invagination during gastrulation.

\section{DISCUSSION}

\section{Similarities and differences in bivalve cleavage patterns}

We found that the cleavage pattern of the Japanese purple mussel, Septifer virgatus, is quite similar to that of four other bivalves that undergo indirect development: Unio complanata (Lillie, 1895), Dreissena polymorpha (Meisenheimer, 1901), Pholas dactylus (Guerrier, 1970) and Saccostrea kegaki (Kakoi et al., 2008; Kin et al., 2009). All five species with indirect development display unequal cleavage as early as the first cell division and fix the dorso-ventral axis before the 4-cell stage, although the polar lobe is not formed in $U$. complanata, $D$. polymorpha, or $P$. dactylus. The 2 d blastomere $(X)$ is the largest cell, as in other species, and undergoes bilaterally symmetric cell division after three asymmetric divisions of $2 d(X)$. The bilateral cell division occurs at the 64 -cell stage in $S$. virgatus but at the 46-cell stage in $S$. kegaki (Kin et al., 2009). The cleavage sequence of $X$ in $D$. polymorpha is more similar to that of $S$. kegaki, with symmetric division at the 49-cell stage (Meisenheimer, 1901). In $U$. comlapanata, it occurs as early as the 38-cell stage. Nevertheless, cell divisions of the 1q (four first quartets: $1 \mathrm{a}, 1 \mathrm{~b}$, $1 c$, and 1d) lineage of $U$. comlapanata are slower than those of other species (Lillie, 1895) (Table 1). In U. comlapanata, only 16 cells are derived from 1q, whereas more than 24 cells have been generated by the comparable stage in the other three species. In bivalves and most molluscs, the $1 \mathrm{q}$ lineage contributes to the formation of the anterior-most ectodermal tissues of the veliger, which include the anterior velum (pretrochal ectoderm) and its first ciliary band and the apical organ, composed of the apical ganglion (Hejnol et al., 2007). Embryos of the three species other than $U$. comlapanata develop into veliger larvae, which use the ciliary band and velum to swim. In contrast, U. comlapanata develops into a glochidium larva, which is parasitic on host

Table 1. Number of cells in each quadrant in embryos at the 45- or 46-cell stage, for four species of bivalve mollusc.

\begin{tabular}{ccccc}
\hline & \multicolumn{4}{c}{ Species } \\
\cline { 2 - 5 } Quadrant & S.virgutus & S.kegaki & U. complanata & D.polymorpha $^{2}$ \\
\hline $1 q$ & 26 & 24 & 16 & 25 \\
$2 q$ & 11 & 13 & 19 & 11 \\
$3 q$ & 8 & 7 & 8 & 7 \\
$4 q$ & - & 2 & 2 & 2 \\
\hline Total & 45 & 46 & 45 & 45 \\
\hline${ }^{1}$ Lillie (1895). & & & \\
${ }^{2}$ Meisenheimer (1901). & &
\end{tabular}

animals such as fish and lacks a well-developed velum. This may account for the retarded division rate of the $1 q$ lineage in U. comlapanata (Lillie, 1895).

\section{Comparison of gastrulation patterns and origin of the bivalve mesoderm}

Our observations of cell movements in early gastrulation showed that $M$ lineage cells initiate the cell invagination of gastrulation (Fig. 6). Lillie (1895) and Meisenheimer (1905) also noted cell movements during gastrulation but suggested that the vegetal blastomeres (A, B, C, and D) initiated gastrulation. Lillie (1895) described $M$ and $2 a$ (called $\mathrm{Y}$ ), which he reported to be the origin of the endomesoderm and ectomesoderm, respectively, as delaminating individual blastomeres before gastrulation. Hence, some variation in cell movements during gastrulation appears likely among bivalve species.

Unfortunately, we could not observe the fate of $\mathrm{M}$ lineage cells after gastrulation, in part because substantial cell migration begins to occur at this stage, along with gastrulation and shell field invagination. The relative positions of blastomeres change drastically at this stage, creating difficulties in identifying blastomeres using our current method. Thus, we could not confirm the fate of $M$ and $Y$ lineage cells or determine whether these lineages actually differentiate into the endomesoderm (posterior mesoderm) and ectomesoderm (anterior mesoderm), respectively. Lillie (1895) posited that the adductor muscle cells, which are a novel structure in bivalves, derive from the ectomesoderm. We explored this issue by examining the expression of molecular markers for mesodermal cells, including twist and $c d x$ (Nederbragt et al., 2002).

\section{Highly conserved unequal cleavage pattern of $X$ and evolution of shell morphogenesis}

We found that $X$ blastomeres of $S$. virgatus display a cleavage pattern that is highly conserved among bivalves. (Fig. 5). One of the most remarkable characteristics of bivalve cleavage is that the second cleavage of the $D$ quadrant yields an animal blastomere (2d) that is larger than 2D. This cleavage has not been observed in other spiralians. Furthermore, the cell division pattern is highly stereotypic. The first three cell divisions of $X$ occur in the spiralian manner, but the vegetal cells $\left(X^{1}\right.$ and $\left.X^{2}\right)$ are smaller in the first two cell divisions, and the animal cell takes over the $X$ blastomere designation, as the $\mathrm{X}$ blastomere nomenclature is reserved for the largest blastomere of the $2 d$ lineage prior to the bilateral cleavage. However, in the third division, the animal cell $\left(X^{3}\right)$ is smaller, and the $X$ blastomere occupies the vegetal position. These asymmetric cell divisions, as well as the following bilaterally symmetric division, are wholly conserved in all four species, suggesting that the small blastomeres $X^{1-3}$ may also perform important roles in bivalve morphogenesis. However, We know little about the fate of these blastomeres. Of interest is that the oyster $d p p$, $S k D p p$, is expressed in $X^{1}$, and Kin et al. (2009) suggested that this $S k D p p$-positive cell migrates to occupy a position below the ligament. If so, then $\mathrm{X}^{1-3}$, which clip the bilaterally divided $\mathrm{X}$ blastomeres both anteriorly and posteriorly (Fig. $5 A$ ), may be involved in the development of the ligament, which is a novel structure in bivalves. 
The bilaterally symmetric division of the presumptive cells of the shell plate anlage is highly suggestive of "bivalve" morphogenesis. However, bilateral cleavage is widely observed in spiralian embryogenesis during the development of the bilateral body plan. The best known example is the bilateral division of the endomesoderm cell lineage ( $M$ blastomere) in gastropods and annelids (Conklin 1897; Wilson 1892). In addition, the $2 d$ cell ( $X$ in bivalves) of the polychaete Platynereis divides bilaterally after two spiral cell divisions (Schneider and Bowerman, 2007). Thus, the bilateral division of $X$ is not likely an invention of bivalves to develop separated shell plates. Instead, bivalves exapted the regulatory mechanism of bilateral cell division to evolve the separated shell plates. In this exaptation process, the atypical spiral cleavage that leaves $2 d(X)$ larger than 2D, making the presumptive shell field cell the largest blastomere in the early embryo, may be an important bivalve innovation. The bilateral division of this large blastomere may allow for the development of two bilaterally symmetric cell populations that form the separated shell fields.

In this study, we traced the cleavage pattern and cell movements to the shell field invagination stage. This is the most detailed description to date of the development of shell field precursor cells, and we present the first evidence that shell field invagination originates with $X$ lineage cells $\left(X^{L 1112}\right.$ and $X^{R 1112}$ ), something that neither Lillie (1895) nor Meisenheimer (1901) documented. This observation strongly suggests that $X$ lineage cells develop into shell field cells. However, we still do not have experimental evidence that $X$ lineage cells truly differentiate into cells that secrete shell matrix. Investigating whether $\mathrm{X}^{1}, \mathrm{X}^{2}$, or $\mathrm{X}^{3}$ contributes to shell field cells or is responsible for ligament development is also important. These issues will be resolved by a future study on the early development of $S$. virgatus. Experimental analyses are more feasible using the larger eggs of this bivalve. The current study will serve as the basis for future studies on the morphogenesis of the bivalve body plan.

\section{ACKNOWLEDGEMENT}

We thank Marine world Oarai aquarium for providing us natural sea water.

\section{REFERENCES}

Chather JN (1967) Cellular interactions in the development of the shell gland of the gastropod, Ilyanassa. J Exp Zool 166: 205224

Conklin EG (1897) The embryology of Crepidula. J Morphol 13: 3209

Dictus WJAG, Damen P (1997) Cell-lineage and clonal-contribution map of the trochopore larva of Patella vulgate (Mollusca). Mech Dev 62: 213-226

Eyster LS, Morse P (1984) Early shell formation during molluscan embryogenesis with new studies on the surf clam, Spisula solidissima. Am zool 24: 871-882
Goulding M (2003) Cell contact-dependent positioning of the D cleavage plane restricts eye development in the Ilyanassa embryo. Development 130: 1181-1191

Guerrier P (1970) Les caractères de la segmentation et la détermination de la polarité dorsoventrale dans le développement de quelques Spiralia. J Embryol Exp Morphol 23: 667-692

Gustafson RG, Reid RGB (1986) Development of the pericalymma larva of Solemya reidi (Bivalvia: Cryptodonta: Solemyidae) as revealed by light and electron microscopy. Mar Biol 93: 411427

Haszprunar G, Schander C, Halanych M (2008) Relationship of higher molluscan taxa. In "Phylogeny and Evolution of the Mollusca" Ed by WF Ponder, DR Lindberg, University of California Press, Berkeley, pp 19-32

Hejnol A, Martindale MQ, Henry JQ (2007) High-resolution fate map of the snail Crepidula fornicata: the origins of ciliary bands, nervous system, and muscular elements. Dev Biol 305: 63-76

Henry JQ, Martindale MQ (1998) Conservation of the spiralian developmental program: cell lineage of the nemertean, Cerebratulus lacteus. Dev Biol 201: 253-269

Kakoi S, Kin K, Wada H (2008) Early development of the Japanese spiny oyster (Saccostrea kegaki): characterization of some genetic markers. Zool Sci 25: 455-464

Kin K, Kakoi S, Wada H (2009) Novel role for $d p p$ in the shaping of bivalve shells revealed in a conserved molluscan developmental program. Dev Biol 329: 152-166

Kniprath E (1981) Ontogeny of the molluscan shell field: a review. Zool Scr 10: 61-79

Lambert JD (2008) Mesoderm in spiralians: the organizer and 4d cell. J Exp Zool 310B: 15-23

Lillie FR (1895) The Embryology of the Unionidae. J Morphol 10: 1100

Luetjens CM, Dorresteijn WC (1995) Multiple alternative cleavage patterns precede uniform larval morphology during normal development of Dreissena polymorpha (Mollusca, Lamellibranchia). Roux Arch Dev Biol 205: 138-149

Meisenheimer J (1901) Entwicklungsgeschichte von Dreissensia polymorpha Pall. Z Wiss Zool 69: 1-137

Nederbragt AJ, Lespinet O, Wageningen SV, Loon AE, Adoutte A, Dictus WJAG (2002) A lophotrochozoan twist gene is expressed in the ectomesoderm of the gastropod mollusk Patella vulgata. EvoDevo 4: 334-343

Saivini-plawen LV, Steiner G (1996) Symapomorphies and plesiomorphies in higher classification of mollusca. In "Origin and Evolutionary Radiation of Mollusca" Ed by JD Taylor, Oxford University Press, Oxford, pp 29-52

Schneider SQ, Bowerman B (2007) $\beta$-Catenin asymmetries after all animal/vegetal oriented cell devisions in Platynereis dumerilii embryos mediate binary cell-fate specification. Dev Cell 13: 7386

Todt C, Okusu A, Schander C, Schwabe E (2008) Solenogastres, Caudofoveata and Polyplacophora. In "Phylogeny and Evolution of the Mollusca" Ed by WF Ponder, DR Lindberg, University of California Press, Berkeley, pp 71-96

Wilison EB (1892) The cell-lineage of Nereis. J Morphol 6: 362-442

(Received March 10, 2009 / Accepted September 8, 2009) 